\title{
BASIC SCIENCE: GYNECOLOGY Resveratrol inhibits the release of soluble fms-like tyrosine kinase (sFlt-1) from human placenta
}

Melissa J. Cudmore, PhD; Wenda Ramma, PhD; Meng Cai, PhD; Takeshi Fujisawa, PhD; Shakil Ahmad, PhD; Bahjat Al-Ani, PhD; Asif Ahmed, PhD

OBJECTIVE: Soluble vascular endothelial growth factor receptor-1 (also know as soluble fms-like tyrosine kinase [sFlt]-1) is a key causative factor of preeclampsia. Resveratrol, a plant phytoalexin, has antiinflammatory and cardioprotective properties. We sought to determine the effect of resveratrol on sFlt-1 release.

STUDY DESIGN: Human umbilical vein endothelial cells, transformed human trophoblast-8 (HTR/SVneo)-8/SVneo trophoblast cells, or placental explants were incubated with cytokines and/or resveratrol. Conditioned media were assayed for sFlt-1 by enzyme-linked immunosorbent assay and cell proteins used for Western blotting.

RESULTS: Resveratrol inhibited cytokine-induced release of sFlt-1 from normal placental explants and from preeclamptic placental ex- plants. Preincubation of human umbilical vein endothelial cells or HTR8/SVneo cells with resveratrol abrogated sFlt-1 release. Resveratrol prevented the up-regulation of early growth response protein-1 (Egr-1), a transcription factor necessary for induction of the vascular endothelial growth factor receptor-1 gene and caused up-regulation of heme oxygenase-1, a cytoprotective enzyme found to be dysfunctional in preeclampsia.

CONCLUSION: In summary, resveratrol can inhibit sFlt-1 release and up-regulate heme oxygenase-1; thus, may offer therapeutic potential in preeclampsia.

Key words: endothelial cells, heme oxygenase-1, placenta, resveratrol, soluble fms-like tyrosine kinase-1

Cite this article as: Cudmore MJ, Ramma W, Cai M, et al. Resveratrol inhibits the release of soluble fms-like tyrosine kinase (sFlt-1) from human placenta. Am J Obstet Gynecol 2012;206:XX.

$\mathrm{L}$ evels of soluble vascular endothelial growth factor (VEGF) receptor-1 (also known as soluble fms-like tyrosine kinase [sFlt]-1) are elevated in pregnan-

From the University/British Heart

Foundation Center for Cardiovascular Science, Queen's Medical Research Institute, University of Edinburgh, Edinburgh (Drs Cudmore, Cai, Fujisawa, Ahmad, Ahmed, and Ramma) and Department of Reproductive and Vascular Biology, Institute for Biomedical Research, College of Medical and Dental Sciences, University of Birmingham, Birmingham (Drs Al-Ani and Ahmed), United Kingdom.

Received July 9, 2011; revised Oct. 26, 2011; accepted Nov. 18, 2011.

Supported by grants from the British Heart Foundation (PG/06/114) and Medical Research Council (G0601295 and G0700288). The authors report no conflict of interest. Reprints: Asif Ahmed, PhD, University/British Heart Foundation Center for Cardiovascular Science, Queen's Medical Research Institute, 47 Little France Crescent, Edinburgh, EH16 4TJ, United Kingdom. a.s.ahmed@ed.ac.uk. 0002-9378/\$36.00 (C) 2012 Mosby, Inc. All rights reserved. doi: 10.1016/j.ajog.2011.11.010 cies complicated with preeclampsia ${ }^{1-3}$ and elevated sFlt-1 generated by preeclamptic placenta is responsible for suppressing angiogenesis. ${ }^{4}$ Adenoviral delivery of sFlt- 1 to pregnant rats mimics the clinical manifestations of preeclamp$\mathrm{sia}^{3}$ and introduction of sFlt- 1 into pregnant mice caused hypertension and proteinuria, which could be reversed by VEGF. ${ }^{5}$ This latter study demonstrated that below a critical threshold level, sFlt-1 fails to elicit preeclamptic-like symptoms; ${ }^{5}$ thus, a therapy that can reduce the circulating levels of free sFlt-1 in women with preeclampsia should alleviate the clinical signs of the condition. Indeed, an elegant study by Thadhani et $\mathrm{al}^{6}$ recently showed that preeclamptic patients undergoing plasma apheresis resulted in approximately a $35 \%$ reduction of circulating sFlt- 1 and was accompanied a reduction and stabilization of maternal blood pressure leading to an increase in gestational age.

Heme oxygenase (HO)-1 confers cytoprotection against tissue and cellular injury. ${ }^{7,8}$ Previous studies from our laboratory showed that the HO pathway inhibits cytokine-induced placental damage ${ }^{9}$ and the release of sFlt- $1,{ }^{10}$ and that $\mathrm{HO}-1^{9}$ and $\mathrm{HO}-2^{11-13}$ are dysregulated in preeclamptic placenta. Furthermore, HO-1 messenger RNA (mRNA) is decreased in the blood of preeclamptic women at term. ${ }^{14}$ Most strikingly, chorionic villous samples (fetal placental cells) from women at just 11 weeks' gestation who went on to develop preeclampsia showed reduced $\mathrm{HO}-1$ mRNA. ${ }^{15}$ Thus, agents capable of substituting for the deficiency or inducing the activity of the HO system and/or reducing the elevated sFlt-1 may have therapeutic potential for alleviating the severity of preeclampsia and, in turn, prolong pregnancy, thereby reducing the complication burden for both mother and neonate.

Resveratrol (trans-3,4',5-trihydroxystilbene) is an antimicrobial agent produced by plants found in a number of fruits, with the most abundant natural source being the skin of grapes. Resveratrol is a cardioprotective agent with antiinflammatory and antioxidant abilities. ${ }^{10}$ It can inhibit low-density lipoprotein oxidation ${ }^{16}$ and platelet aggregation, ${ }^{17}$ down-regulate tissue factor expression, ${ }^{18}$ and suppress agonist-induced monocyte adhesion to human 


\section{FIGURE 1}

Resveratrol inhibits sFlt-1 release from placental explants
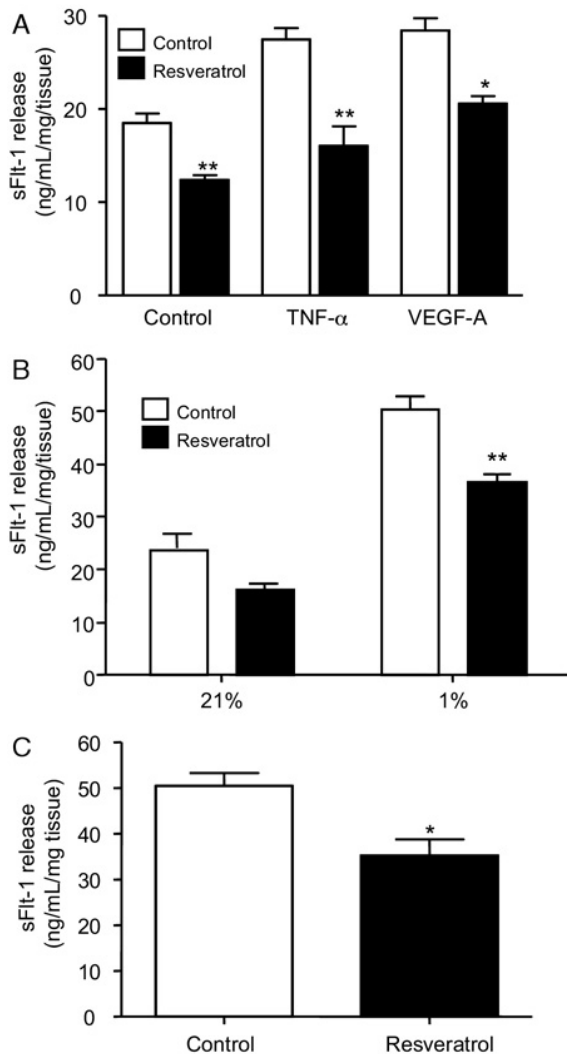

A, Placental villous explants incubated with resveratrol $(100 \mu \mathrm{mol} / \mathrm{L})$, tumor necrosis factor (TNF)- $\alpha(10 \mathrm{ng} / \mathrm{mL})$, and/or vascular endothelial growth factor (VEGF)-A (20 ng/mL) or B, under hypoxia (1\% oxygen) for 24 hours. C, Preeclamptic placental villous explants were incubated in presence of resveratrol (100 $\mu \mathrm{mol} / \mathrm{L})$. Conditioned media were collected and assayed for sFlt-1 by enzyme-linked immunosorbent assay. Data are from 3 normal and 3 preeclamptic placentas and are expressed as $\mathrm{ng} / \mathrm{mL}$ of free and bound sFlt-1/mg of placental tissue and are mean ( \pm SEM) experiments performed in duplicate.

sFlt, soluble fms-like tyrosine kinase.

${ }^{\star} P<.05$ vs control; ${ }^{* *} P<.01$ vs control.

Cudmore. Resveratrol inhibits sFlt-1 and induces HO-1. Am J Obstet Gynecol 2012.

umbilical vein endothelial cells (HUVEC). ${ }^{19}$ Moreover, resveratrol was shown to modulate nitric oxide (NO) production, ${ }^{20}$ up-regulate endothelial NO synthase, ${ }^{21}$ prevent generation of reactive oxygen species, ${ }^{22}$ and up-regulate HO-1 expression. ${ }^{23-25}$ As an anticancer agent, resveratrol can restrain tumor initiation and progression, and suppress metastasis. ${ }^{26,27}$

Resveratrol has been safely administered to healthy volunteers at very high doses and caused no serious adverse effects. ${ }^{28}$ In rats, embryo-fetal toxicity studies showed no adverse effects of high-dose resveratrol, ${ }^{29}$ and daily administration to mice from gestational day 8 onward did not affect fetal/placental growth and even reversed dioxin-induced teratogenicity. ${ }^{30,31}$ In addition, in a murine model of diabetic pregnancy, resveratrol was found to prevent embryonic oxidative stress and apoptosis and improve the glucose and lipid profile of diabetic mothers. ${ }^{32}$ Thus, it is likely that resveratrol would be a safe and beneficial drug to give during pregnancy, but proof-of-concept studies and toxicology would evidently need to be rigorous before therapeutic use is initiated.

In this study, we investigated the effects of resveratrol on sFlt-1 and HO-1 expression in placental villous explants, trophoblasts, and endothelial cells. We show that resveratrol significantly inhibits sFlt-1 release and up-regulates $\mathrm{HO}-1$, thus demonstrating that resveratrol has the potential to be investigated as a therapeutic agent for preeclampsia.

\section{Materials and Methods Reagents and antibodies}

Recombinant VEGF was purchased from ReliaTech (Braunschweig, Germany). Antibodies for the sFlt-1 enzyme-linked immunosorbent assay (ELISA) were purchased from R and D Systems (Abingdon, UK). Early growth response protein-1 (Egr-1) antibody was from Autogen Bioclear Ltd (Wiltshire, UK). Polyclonal rabbit anti-HO-1 antibody was purchased from StressGen Biotechnologies Corp (Victoria, British Columbia, Canada). Angiotensin II, phorbol-12-myristate-13-acetate (PMA), resveratrol, tumor necrosis factor (TNF) $-\alpha$, interferon- $\gamma$, mouse anti- $\beta$-actin, and all other cell culture reagents were purchased from Sigma-Aldrich Ltd (Dorset, UK).

\section{Cell culture}

HUVEC were isolated from umbilical cords, characterized, and cultured as previously described. ${ }^{4}$ The transformed human trophoblast-8 (HTR-8/SVneo) cell line were grown in Roswell Park Memorial
Institute (RMPI) medium containing 10\% fetal calf serum (FCS).

\section{Placental tissue collection and explant culture}

Human placental tissue was obtained from normal pregnancies and gestationally matched pregnancies complicated by preeclampsia. Preeclampsia was defined as blood pressure $>140 / 90 \mathrm{~mm} \mathrm{Hg}$ on at least 2 consecutive measurements and proteinuria of at least $300 \mathrm{mg}$ per 24 hours. Informed consent was obtained from the patients and the study had the approval of the South Birmingham Ethical Committee (Birmingham, UK) and the Edinburgh Reproductive Tissue BioBank (Edinburgh, UK). Villous explants were prepared as described previously ${ }^{4,9}$ and incubated in the presence or absence of resveratrol $(100 \mu \mathrm{mol} / \mathrm{L}), \operatorname{VEGF}(20$ $\mathrm{ng} / \mathrm{mL}), \mathrm{TNF}-\alpha(50 \mathrm{ng} / \mathrm{mL})$, or under hypoxia (1\% oxygen) and conditioned media assayed for sFlt-1 by ELISA.

\section{ELISA for sFlt-1}

sFlt-1 levels in culture supernatants were measured as previously described. ${ }^{4,10}$

\section{MTT assay for cell viability}

HUVEC were seeded at a density of $5 \times$ $10^{4}$ cells/well in a 96-well plate, left to attach for 4 hours, and then rested overnight in medium containing 5\% FCS. Cells were incubated with resveratrol for 24 hours, then 3-(4,5-Dimethylthiazol2-yl)-2,5-diphenyltetrazolium bromide (MTT) $(5 \mathrm{mg} / \mathrm{mL})$ was added and cells incubated in the dark at $37^{\circ} \mathrm{C}$ for 4 hours. MTT was aspirated and reconstituted in dimethyl sulfoxide (DMSO). Optical density values were measured at 540 and $690 \mathrm{~nm}$

\section{Western blotting}

Proteins were extracted from cells and subjected to Western blot analysis as previously described. ${ }^{4} \mathrm{HUVEC}$ were either preincubated with resveratrol $(100 \mu \mathrm{mol} / \mathrm{L})$ for 30 minutes prior to addition of PMA $(10 \mathrm{nmol} / \mathrm{L})$ for 2 and 4 hours or incubated for 24 hours with resveratrol, and then lysates in radioimmunoprecipitation assay buffer were subjected to sodium dodecyl sulfate polyacrylamide gel electrophoresis (SDS-PAGE) on $15 \%$ gels and Western blotted with rabbit anti-Egr-1 antibody 
(Autogen Bioclear Ltd) or rabbit antiHO-1 antibody (StressGen Biotechnologies Corp).

\section{Quantitative real-time polymerase chain reaction}

Sample preparation and real-time polymerase chain reaction was performed as described previously. ${ }^{33}$ Briefly, mRNA was prepared using TRIzol and DNase-1 digestion/purification on RNAeasy columns (Qiagen, West Sussex, UK), and reverse transcribed with the complementary DNA (cDNA) synthesis kit (Promega, Hampshire, UK). Triplicate cDNA samples and standards were amplified in SensiMix containing SYBR green (Quantace, London, UK) with primers specific for $\mathrm{HO}-1$ (sense: $5^{\prime}$ GGG TGA TAG AAG AGG CCA AGA CT- $3^{\prime}$ and anti-sense: $5^{\prime}$-GCA GAA TCT TGC ACT TTG TTG CT- $\left.3^{\prime}\right)^{34}$ or $\beta$-actin. The mean threshold cycle $\left(\mathrm{C}_{\mathrm{T}}\right)$ for each $\mathrm{HO}-1$ was normalized to $\beta$-actin and expressed relative to control.

\section{Statistical analysis}

All data are expressed as mean \pm SEM. For placental studies, data are from 3 normal and 3 preeclamptic placentas and experiments were performed in duplicate. For HUVEC, all experiments were performed on cells from 3 separate pooled preparations of HUVEC, and each stimulation was performed in triplicate on the cell preparations. For the cell line, HTR-8/SVneo, 3 experiments were performed in duplicate. Blots are representative of 3 experiments. Statistical comparisons were performed using 1-way analysis of variance followed by the Student-Newman-Keuls test as appropriate. Statistical significance was set at a value of $P<.05$.

\section{RESUlTS}

Resveratrol inhibits cytokine- and hypoxia-induced sFIt-1 release from placental explants

To determine whether resveratrol affects placental sFlt-1 release, normal placental villous explants were incubated with resveratrol, with or without TNF- $\alpha$ or VEGF, for 24 hours and sFlt- 1 assayed in the conditioned medium. Resveratrol inhibited sFlt-1 release under basal and

\section{FIGURE 2}

Resveratrol inhibits sFlt-1 release from trophoblasts and endothelial cells
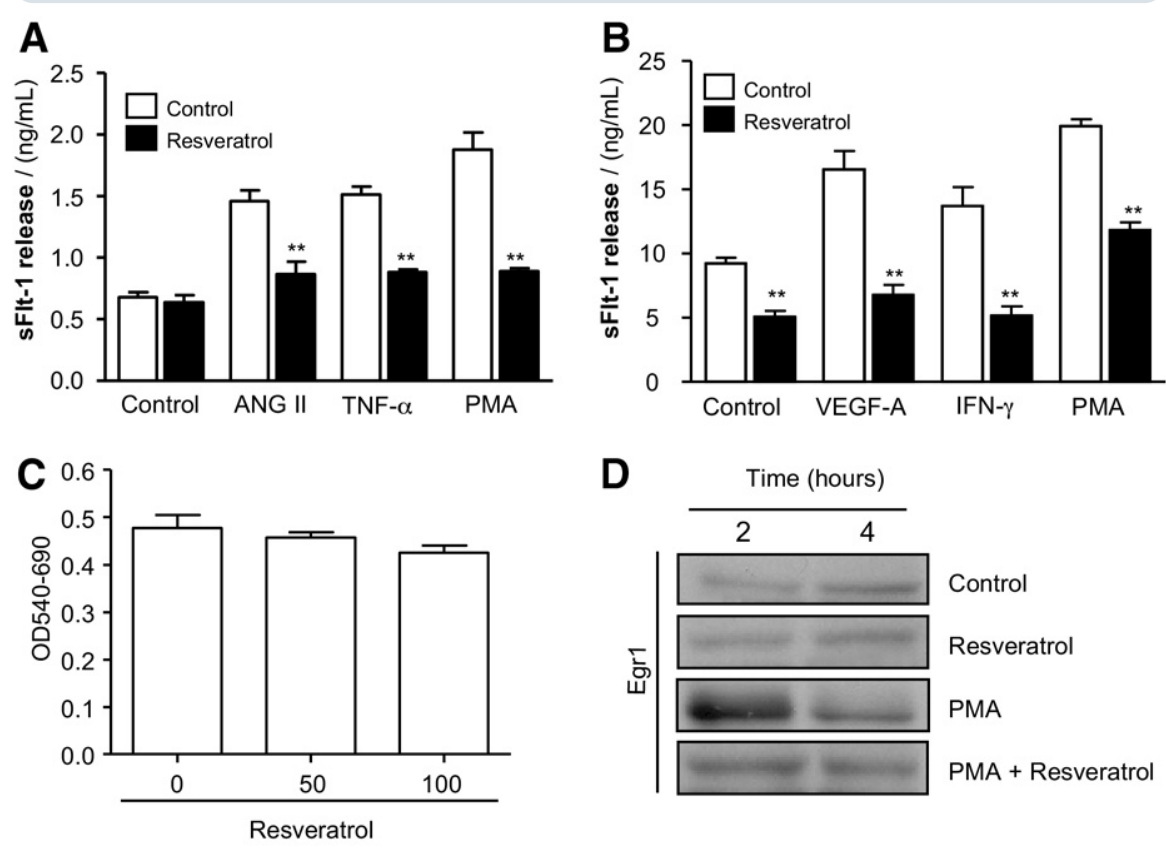

A, Transformed human trophoblast-8 (HTR/SVneo) cells incubated with resveratrol (100 $\mu \mathrm{mol} / \mathrm{L})$, angiotensin (ANG) II (10 ng/mL), tumor necrosis factor (TNF)- $\alpha$ (10 ng/mL), and/or PMA (10 nmol/L) for 24 hours. B, Human umbilical vein endothelial cells (HUVEC) incubated with resveratrol (100 $\mu \mathrm{mol} / \mathrm{L})$, vascular endothelial growth factor (VEGF)-A (20 ng/mL), interferon (IFN)- $\gamma(10 \mathrm{ng} / \mathrm{mL})$, and/or PMA (10 nmol/L) for 24 hours. Data are expressed as $\mathrm{ng} / \mathrm{mL}$ of free and bound sFlt-1 and are mean ( \pm SEM) of 3 separate experiments performed in duplicate. C, HUVEC were incubated with resveratrol (100 $\mu \mathrm{mol} / \mathrm{L})$ for 24 hours prior to MTT assay. D, HUVEC were incubated with resveratrol $(100 \mu \mathrm{mol} / \mathrm{L})$ and/or PMA (10 nmol/L) for 2 and 4 hours and cell lysates Western blotted for Egr-1. Representative Western blot.

$s F I t$, soluble fms-like tyrosine kinase.

${ }^{\star \star} P<.01$ vs control.

Cudmore. Resveratrol inhibits sFlt-1 and induces HO-1. Am J Obstet Gynecol 2012.

cytokine-stimulated conditions in placental explants from normal pregnancies (Figure 1, A). When placental explants were incubated in hypoxic conditions sFlt-1 release into the media was elevated and incubation with resveratrol inhibited this (Figure 1, B). sFlt-1 is greatly elevated in preeclampsia, with the level correlating to the severity of the condition. To assess whether resveratrol had inhibitory effects on the elevated sFlt-1 release from preeclamptic placenta, preeclamptic explants were incubated with resveratrol for 24 hours. This resulted in almost $20 \%$ reduction in sFlt- 1 release compared with vehicle-treated explants (Figure 1, C), thus demonstrating that resveratrol can decrease
sFlt-1 expression regardless of placental condition.

\section{Resveratrol inhibits sFlt-1 release from trophoblasts and endothelial cells}

Both the endothelial cells and trophoblasts of the placenta have been shown to secrete sFlt-1. Resveratrol inhibited release of sFlt-1 from the first-trimester HTR-8/ SVneo trophoblast cell line after induction with angiotensin II, TNF- $\alpha$, and the protein kinase $\mathrm{C}$ (PKC) activator, PMA (Figure 2,A). Likewise, resveratrol significantly reduced sFlt-1 release from HUVEC, both under basal condition and after stimulation (Figure 2, B). Resveratrol was not toxic to endothelial cells (Figure 2, C). Res- 
FIGURE 3

Resveratrol up-regulates $\mathrm{HO}-1$ in trophoblasts and endothelial cells

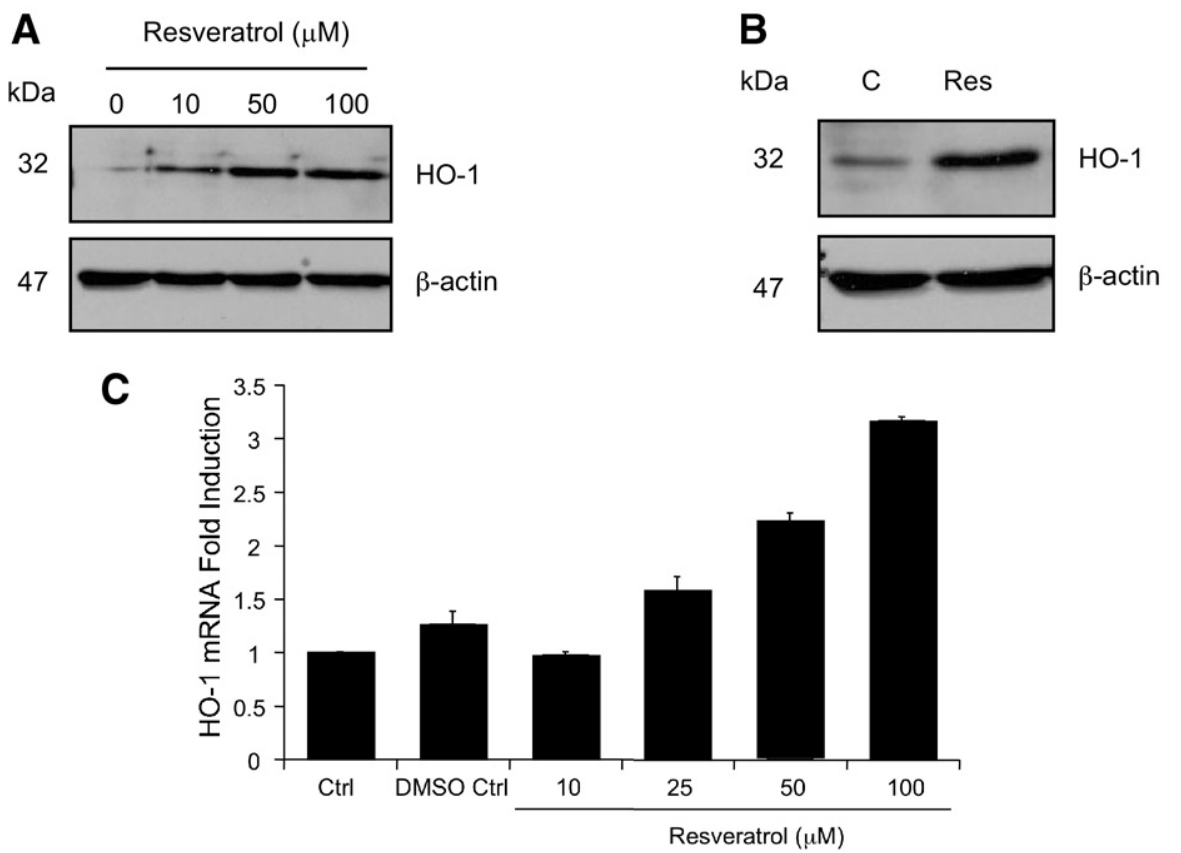

A, Human umbilical vein endothelial cells (HUVEC) and $\mathbf{B}$, transformed human trophoblast-8 (HTR/ SVneo) cells were incubated with resveratrol (Res, $100 \mu \mathrm{mol} / \mathrm{L}$ ) or control (C) for 24 hours and cell lysates Western blotted for heme oxygenase (HO)-1. Representative Western blot. C, HUVEC were incubated with resveratrol, dimethyl sulfoxide (DMSO) control or water control (Ctrl) and messenger RNA (mRNA) probed for $\mathrm{H} 0-1$ by quantitative polymerase chain reaction (expressed as $\mathrm{HO}-1$ fold induction normalized to $\beta$-actin).

Cudmore. Resveratrol inhibits sFlt-1 and induces HO-1. Am J Obstet Gynecol 2012.

veratrol directly inhibited activation of the Flt-1 promoter (Appendix; Supplemental Figure, A) and prevented up-regulation of the transcription factor, Egr-1 (Figure 2, D), which has been shown to be important for induction of the flt-1 gene. $^{35}$

\section{Resveratrol induces endothelial and trophoblast H0-1 expression}

Reduced HO-1 expression and activity has been demonstrated in placenta from preeclamptic pregnancies. ${ }^{9}$ Incubation of HUVEC (Figure 3, A) or HTR-8/SVneo cells (Figure 3, B) with resveratrol for 24 hours induced the expression of HO- 1 and up-regulated HO-1 mRNA in a concentration-dependent manner (Figure 3, C). In addition, resveratrol also activated the HO-1 promoter (Supplemental Figure, B).

\section{Comment}

In a screen for novel agents with therapeutic potential for treating preeclampsia, we discovered that resveratrol, a plant phytoalexin, found in high concentrations in the skin of grapes, significantly inhibits sFlt-1 release from placental tissues, trophoblasts, and endothelial cells. Furthermore, resveratrol causes up-regulation of the protective enzyme, $\mathrm{HO}-1$, which was found to be reduced in placenta from preeclamptic pregnancies. These results, demonstrating that resveratrol can overcome 2 of the pathogenic mechanisms associated with preeclampsia, present the possibility that resveratrol has the potential to be investigated as a therapeutic agent for preeclampsia.

Even though eclampsia was first described 4000 years ago, preeclampsia and eclampsia still complicate up to $10 \%$ of pregnancies and both their cause and cure remain elusive. The World Health Organization reports $>60,000$ maternal deaths worldwide annually as a consequence of preeclampsia and $\sim 12 \%$ of their babies die within the first month.
Preeclampsia is responsible for $30 \%$ of all premature deliveries and is associated with approximately 4 million intrauterine growth-restricted babies. Moreover, preeclampsia also impacts health long term. Systematic review and metaanalysis showed that women with preeclampsia are at a 2-fold increased risk of developing cardiovascular disease later in life. ${ }^{36}$ Thus, the global social and economic burden of preeclampsia is immense and still the only effective therapy is delivery of the baby and placenta. Any intervention achieving a modest improvement in mean pregnancy length or birthweight will improve the lives of tens of thousands of women and their offspring. The finding that the naturally available plant compound, resveratrol, has the ability to inhibit sFlt-1 release and up-regulate $\mathrm{HO}-1$ means it has the potential to ameliorate the symptoms of preeclampsia. Prior to initiation of human clinical trials, proof-of-concept experiments need to be carried out in animal models of preeclampsia, to ascertain whether resveratrol up-regulates $\mathrm{HO}-1$ and inhibits sFlt-1 in this setting. One current drawback to the clinical use of resveratrol is its well-known limited in vivo bioavailability. However, there are numerous strategies currently under development to overcome this due to the multitude of potential benefits this drug has been shown to have to human health. ${ }^{37}$ In addition, it is possible that resveratrol may have to be administered intravenously, as opposed to orally, to have the best effect. Subsequently, a randomized placebo-controlled trial would be needed in women who develop earlyonset preeclampsia. Once an accurate predictive test is designed and established, women destined to develop earlyonset preeclampsia could be offered preventative resveratrol therapy. If these studies prove successful, then the therapy could be offered to women destined to develop milder forms of the disorder.

Resveratrol also has benefits against other pathogenic processes that are apparent in preeclampsia. It has a positive modulatory function on NO release, ${ }^{20}$ and endothelial NO synthase expression, ${ }^{21}$ both of which are compromised in preeclampsia. ${ }^{38}$ In addition, resvera- 
trol has inhibitory functions on platelet aggregation, ${ }^{17}$ reactive oxygen species generation, ${ }^{22}$ and leukocyte adhesion, ${ }^{19}$ along with mechanisms prevalent in the disorder. In conclusion, in vivo study of this compound is warranted to assess whether these promising in vitro findings can be translated into therapy.

\section{REFERENCES}

1. Ahmad $S$, Ahmed A. Regulation of soluble VEGFR- 1 by VEGF and oxygen and its elevation in pre-eclampsia and fetal growth restriction. Placenta 2001;22:A7.

2. Vuorela $P$, Helske S, Hornig C, Alitalo K, Weich $\mathrm{H}$, Halmesmäki E. Amniotic fluid-soluble vascular endothelial growth factor receptor-1 in preeclampsia. Obstet Gynecol 2000;95:353-7. 3. Maynard SE, Min JY, Merchan J, et al. Excess placental soluble fms-like tyrosine kinase 1 (sFlt1) may contribute to endothelial dysfunction, hypertension, and proteinuria in preeclampsia. J Clin Invest 2003;111:649-58.

4. Ahmad S, Ahmed A. Elevated placental soluble vascular endothelial growth factor receptor-1 inhibits angiogenesis in preeclampsia. Circ Res 2004;95:884-91.

5. Bergmann A, Ahmad S, Cudmore M, et al. Reduction of circulating soluble Flt-1 alleviates preeclampsia-like symptoms in a mouse model. J Cell Mol Med 2010;14:1857-67.

6. Thadhani R, Kisner T, Hagmann H, et al. Pilot study of extracorporeal removal of soluble fmslike tyrosine kinase 1 in preeclampsia. Circulation 2011;124:940-50.

7. Otterbein LE, Kolls JK, Mantell LL, Cook JL, Alam J, Choi AM. Exogenous administration of heme oxygenase- 1 by gene transfer provides protection against hyperoxia-induced lung injury. J Clin Invest 1999;103:1047-54.

8. Dulak J, Deshane J, Jozkowicz A, Agarwal A. Heme oxygenase-1 and carbon monoxide in vascular pathobiology: focus on angiogenesis. Circulation 2008;117:231-41.

9. Ahmed A, Rahman M, Zhang X, et al. Induction of placental heme oxygenase-1 is protective against TNFalpha-induced cytotoxicity and promotes vessel relaxation. Mol Med 2000;6: 391-409.

10. Cudmore M, Ahmad S, Al-Ani B, et al. Negative regulation of soluble Flt-1 and soluble endoglin release by heme oxygenase-1. Circulation 2007;115:1789-97.

11. Wang YP, Yu YH. Expression of endogenous heme oxygenase on surface of placental trophoblasts of pregnant women with intrauterine growth retardation of the fetus. Di Yi Jun Yi Da Xue Xue Bao 2002;22:637-9.

12. Lash GE, Mclaughlin BE, MacDonald SK, et al. Relationship between tissue damage and heme oxygenase expression in chorionic villi of term human placenta. Am J Physiol Heart Circ Physiol 2003;284:H160-7.
13. Zenclussen AC, Lim E, Knoeller S, et al. Heme oxygenases in pregnancy $\mathrm{I}$ : $\mathrm{HO}-2$ is down-regulated in human pathologic pregnancies. Am J Reprod Immunol 2003;50:66-76.

14. Nakamura $M$, Sekizawa $A, P$ urwosunu $Y$, et al. Cellular mRNA expressions of anti-oxidant factors in the blood of preeclamptic women. Prenat Diagn 2009;29:691-6.

15. Farina A, Sekizawa $A$, De Sanctis $P$, et al. Gene expression in chorionic villous samples at 11 weeks' gestation from women destined to develop preeclampsia. Prenat Diagn 2008;28: 956-61.

16. Frankel EN, Waterhouse AL, Kinsella JE. Inhibition of human LDL oxidation by resveratrol. Lancet 1993;341:1103-4.

17. Bertelli AA, Giovannini L, Giannessi D, et al. Antiplatelet activity of synthetic and natural resveratrol in red wine. Int J Tissue React 1995; 17:1-3.

18. Di Santo A, Mezzetti A, Napoleone E, et al. Resveratrol and quercetin down-regulate tissue factor expression by human stimulated vascular cells. J Thromb Haemost 2003;1:1089-95.

19. Pendurthi UR, Rao LV. Resveratrol suppresses agonist-induced monocyte adhesion to cultured human endothelial cells. Thromb Res 2002;106:243-8.

20. Kampa M, Hatzoglou A, Notas G, et al. Wine antioxidant polyphenols inhibit the proliferation of human prostate cancer cell lines. Nutr Cancer 2000;37:223-33.

21. Wallerath T, Deckert G, Ternes T, et al. Resveratrol, a polyphenolic phytoalexin present in red wine, enhances expression and activity of endothelial nitric oxide synthase. Circulation 2002;106:1652-8.

22. Sgambato A, Ardito R, Faraglia B, Boninsegna A, Wolf FI, Cittadini A. Resveratrol, a natural phenolic compound, inhibits cell proliferation and prevents oxidative DNA damage. Mutat Res 2001;496:171-80.

23. Chen CY, Jang JH, Li MH, Surh YJ. Resveratrol up-regulates heme oxygenase-1 expression via activation of NF-E2-related factor 2 in PC12 cells. Biochem Biophys Res Commun 2005;331:993-1000.

24. Juan SH, Cheng TH, Lin HC, Chu YL, Lee WS. Mechanism of concentration-dependent induction of heme oxygenase-1 by resveratrol in human aortic smooth muscle cells. Biochem Pharmacol 2005;69:41-8.

25. Das S, Fraga CG, Das DK. Cardioprotective effect of resveratrol via $\mathrm{HO}-1$ expression involves p38 map kinase and PI-3-kinase signaling, but does not involve NFkappaB. Free Radic Res 2006;40:1066-75.

26. Baur JA, Sinclair DA. Therapeutic potential of resveratrol: the in vivo evidence. Nat Rev Drug Discov 2006;5:493-506.

27. Athar $M$, Back JH, Tang $X$, et al. Resveratrol: a review of preclinical studies for human cancer prevention. Toxicol Appl Pharmacol 2007;224:274-83.

28. Boocock DJ, Faust GE, Patel KR, et al. Phase I dose escalation pharmacokinetic study in healthy volunteers of resveratrol, a potential cancer chemopreventive agent. Cancer Epidemiol Biomarkers Prev 2007;16:1246-52. 29. Williams LD, Burdock GA, Edwards JA, Beck M, Bausch J. Safety studies conducted on high-purity trans-resveratrol in experimental animals. Food Chem Toxicol 2009;47:2170-82. 30. Jang JY, Park D, Shin S, et al. Antiteratogenic effect of resveratrol in mice exposed in utero to 2,3,7,8-tetrachlorodibenzo-p-dioxin. Eur J Pharmacol 2008;591:280-3.

31. Singh NP, Singh US, Nagarkatti M, Nagarkatti PS. Resveratrol (3,5,4'-trihydroxystilbene) protects pregnant mother and fetus from the immunotoxic effects of 2,3,7,8-tetrachlorodibenzo-p-dioxin. Mol Nutr Food Res 2011;55: 209-19.

32. Singh CK, Kumar A, Hitchcock DB, et al. Resveratrol prevents embryonic oxidative stress and apoptosis associated with diabetic embryopathy and improves glucose and lipid profile of diabetic dam. Mol Nutr Food Res 2011;55:1186-96

33. Ahmad S, Hewett PW, Wang P, et al. Direct evidence for endothelial vascular endothelial growth factor receptor-1 function in nitric oxide-mediated angiogenesis. Circ Res 2006;99: 715-22.

34. Smith G, Dawe RS, Clark C, et al. Quantitative real-time reverse transcription-polymerase chain reaction analysis of drug metabolizing and cytoprotective genes in psoriasis and regulation by ultraviolet radiation. J Invest Dermatol 2003;121:390-8.

35. Morishita K, Johnson DE, Williams LT. A novel promoter for vascular endothelial growth factor receptor (flt-1) that confers endothelialspecific gene expression. J Biol Chem 1995; 270:27948-53

36. Bellamy L, Casas JP, Hingorani AD, Williams DJ. Pre-eclampsia and risk of cardiovascular disease and cancer in later life: systematic review and meta-analysis. BMJ 2007;335:974. 37. Amri A, Chaumeil JC, Sfar S, Charrueau C. Administration of resveratrol: what formulation solutions to bioavailability limitations? J Control Release 2011 Sep 25 [Epub ahead of print].

38. Beinder E, Mohaupt MG, Schlembach D, et al. Nitric oxide synthase activity and Doppler parameters in the fetoplacental and uteroplacental circulation in preeclampsia. Hypertens Pregnancy 1999;18:115-27.

\section{Appendix \\ Supplemental Method Promoter reporter assays}

Cells were transfected with either a human flt-1 or hmox-1 promoter-luciferase construct using Exgen 500 (Fermentas, York, UK) prior to incubation with resveratrol $(100 \mu \mathrm{mol} / \mathrm{L})$ for 24 hours. Cells were lysed and accumulated luminescence was assessed with a luminometer. 


\section{SUPPLEMENTAL FIGURE \\ Resveratrol inhibits fit-1 \\ promoter, but activates hmox-1 \\ promoter}

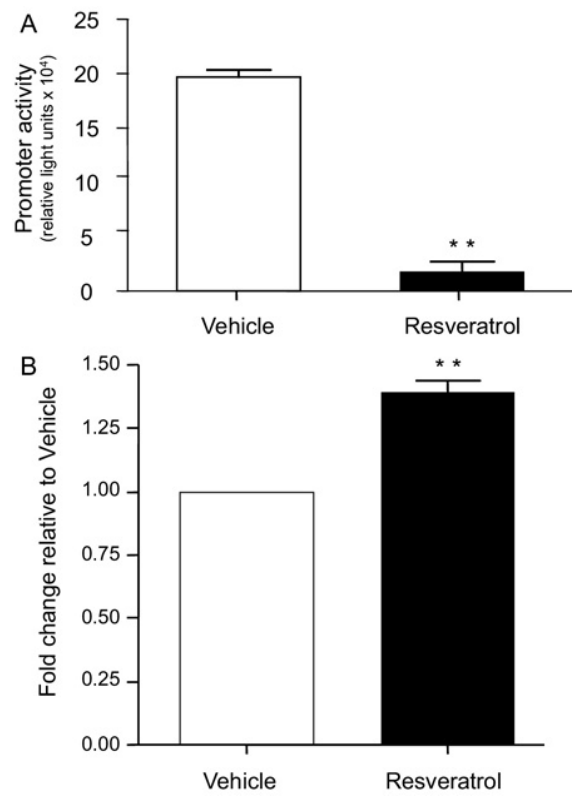

Cells were transfected with promoter reporter constructs for A, flt-1 and B, hmox-1 genes. Cells were incubated with resveratrol (100 $\mu \mathrm{mol} / \mathrm{L})$ for 24 hours, after which time accumulated luminescence was assessed with a luminometer.

$s F l t$, soluble fms-like tyrosine kinase.

${ }^{* \star} P<.01$ vs vehicle.

Cudmore. Resveratrol inhibits sFlt-1 and induces HO-1. Am J Obstet Gynecol 2012. 